\title{
Physiological, Growth, and Immune Responses of Japanese Quail Chicks to the Multiple Stressors of Immunological Challenge and Lead Shot
}

\author{
J. M. Fair, ${ }^{1,2}$ R. E. Ricklefs ${ }^{2}$ \\ ${ }^{1}$ Los Alamos National Laboratory, Environmental Dynamics and Spatial Analysis, EES-10, MS J495, Los Alamos, New Mexico 87545, USA \\ ${ }^{2}$ University of Missouri-St. Louis, Department of Biology, 8001 Natural Bridge, St. Louis, Missouri 63121, USA
}

Received: 5 February 2001/Accepted: 15 July 2001

\begin{abstract}
Exposure to the combination of a contaminant and an immunological challenge during development may greatly increase the impact of either or both of these stressors on an individual. This study investigated the interacting effects of a nonpathogenic immunological challenge and lead shot exposure early in the development of a precocial species. Seventyone quail (Coturnix coturnix japonica) chicks orally received either one \#9 lead shot $(0.05 \mathrm{~g})$, four lead shots $(0.2 \mathrm{~g})$, or no lead at the age of 8 days. A third of each of these groups of chicks were intraperitoneally injected with either $0.075 \mathrm{ml}$ of $10 \%$ chukar (Alectoris graeca) red blood cells (CRBCs), Newcastle disease virus (NDV), or a placebo oil vaccine at 13 and 35 days of age. There was no difference in the survival between any of the lead or antigen treatment groups. Lead concentrations in blood were greater for the lead-dosed groups on day 49 but not on day 128. Growth curves were approximated by Weibull functions; growth parameters did not differ between lead-treated and antigen-treated birds. CRBC antigen increases fluctuating asymmetry (FA) for primary feather five, while NDV reduced FA. Lead did not affect antibody production or cell-mediated immune response. White blood cell numbers increased 7 days after antigen injection on days 27 and 49 of age. Granulocyte numbers were significantly higher for the lead-treated quail than the control quail, and both antigentreated groups had lower granulocyte numbers than control quail. The treatment groups of combining NDV and lead shot had an average plasma protein 14\% lower than other groups. Lead shot in the highest of these doses lowered asymptotic weights, increased hematocrits, lowered plasma protein, and increased granulocyte numbers of quail.
\end{abstract}

Exposure to a contaminant and an immunological challenge during development may greatly increase the impact of either or both of the stressors on an individual. Exposure to multiple stressors would inherently be more common in wild populations of animals than single-dosed animals used in most toxi-

Correspondence to: J. M. Fair; email: jmfair@lanl.gov cology studies, thus confounding the extrapolation of these results to wild animals. Due to the multitude of both pathogenic and nonpathogenic immunogens, in addition to contaminants to which wild birds may be exposed during development, it is important to understand how the immune system and growth responds to both contaminants and immunogens together. Exposure of developing birds to environmental stressors may have several physiological consequences, including a decrease in immunocompetence. Mounting an immune response to foreign antigens may constitute a cost for developing birds and result in decreased growth, perhaps with long-term consequences for fitness (Gebhardt-Henrich and Richner 1998). Immune responses to nonpathogenic antigens, such as vaccines, have been shown to impair growth performance and developmental stability in domestic chickens (Klasing et al. 1987) and Japanese quail (Fair et al. 1999). Svennson et al.'s (1998) data support the idea that a trade-off may occur between immunocompetence and energetically costly activities, such as thermoregulation, reproduction, or mate attraction. Additional costs of damage from contaminant exposure may cause the organism to reallocate energy expenditures to repair the affected system. Reallocation will most likely be reflected in reduced growth and metabolic rate and may indirectly affect immunocompetence.

Although intraspecific variation in growth has numerous sources (Gebhardt-Henrich and Richner 1998), no investigation has been conducted of the additive effects on growth of a contaminant and immunological challenges by different types of antigens. Immune responses impose two costs that affect growth: (1) maintaining a functioning immune system and (2) mounting a specific or nonspecific immune response. Growth responses to nonpathogenic antigen challenges may be mediated through the reallocation of limited resources, although this may impose only a small cost (Klasing 1998). Alternatively, the effects of mounting an immune response may be exerted through systemic physiological controls on metabolic and developmental pathways.

Lead has immunosuppressive effects in animals, including birds (Koller 1973; Franson 1984; Trust et al. 1990; Youssef 1996). Grasman and Scanlon (1995) investigated the interacting effects of acute lead exposure and diets on antibody and T-cell-mediated immunity in Japanese quail and found differ- 
ences in immunological responses among groups of birds maintained on different diets. The idea of an additive response to multiple stressors on organisms is not a new concept, but it is often omitted from ecological risk assessments when applying laboratory-based toxicological data to field situations because there is no good information on these types of responses. Therefore, it is vital to determine the degree to which effects of contaminants add to those of other stressors on organisms in the wild, including food limitation, immunological challenges by pathogens, cold exposure, and parasites. In this study, nonpathogenic immunological challenges in combination with two levels of lead shot were evaluated.

A common method of quantifying humoral response is to measure antibody production following introduction of a nonpathogenic antigen. Peak antibody titers are usually reached in 5 to 15 days of age in chickens (Nelson et al. 1995). Antigen challenge is potentially a useful tool for investigating effects of various stressors in the environment on organism performance. However, the costs of mounting immune responses could be an important confounding factor in such studies, particularly those involving young chicks with immature and developing immune systems.

The growth of nestling birds is commonly used as an index to environmental and genetic stress (e.g., Richner et al. 1989; Eeva and Lehikoinen 1996). In addition to body mass and the lengths of feathers and appendages, asymmetric development of bilateral characters has been suggested as another indicator of the effects of stress on development (Swaddle and Whitter 1994). Presumably, the growth of each of a pair of bilateral characters is influenced by the same genetic and environmental factors. Accordingly, small errors in development could cause random deviations from perfect symmetry (fluctuating asymmetry, or FA) and thus provide a combined measure of innate developmental stability and stress on the growing individual (Teather 1996; Møller and Swaddle 1997).

The variance in the length of a bilateral character has several components, only one of which includes FA. These components may be quantified by analysis of variance using an approach outlined by Palmer and Strobeck (1986). FA has been used in numerous studies as an indicator of developmental stability and presumably reflects the influences of both environmental and genetic stress on development in both plants and animals (Bonn et al., 1996; Sarre 1996; Bernhard Rabitsch 1997; Stanton and Roy 1999). Most such studies have addressed the relationship between the asymmetry of adult characters and genetic or environmental perturbations (e.g., Teather 1996), presuming that environmental and/or genetic stress during ontogeny may interfere with the precise regulation of developmental processes and thereby result in an increase in FA (Clarke 1993a). The relationship between growth, FA, and stress imposed by challenges to the immune system has not been investigated, except by Fair et al. (1999) that found FA increased with immunological challenge.

Additional measures of stress in studies of laboratory and natural populations of animals include circulating levels of protein in the blood which are thought to vary in relation to total protein reserves in an animal (Allison 1955). Total plasma protein levels also may become elevated when dietary protein intake increases (Leveille and Sauberlich 1961) and thus indicate improved physiological condition in wild birds (Dawson and Bortolotti 1997). Although total plasma protein can vary with sex and breeding stage, and typically declines in nestlings as the breeding season progresses (Dawson and Bortolotti 1997), little is known of the relationship between either packed cell volume (hematocrit) or total plasma protein and immunological and growth parameters. More research is needed to validate both hematocrit and plasma protein as indicators of stress and condition because immune response may cause changes in both packed-cell volume and total plasma protein.

Japanese quail (Coturnix coturnix japonica) are frequently used as indicators in avian toxicity tests (Romijn et al. 1995) and are one of the most often studied avian species. They were therefore a logical choice for this study. We focused on chicks because they represent a vulnerable stage of the life cycle and offer the potential for competition between growth, immune responses, and effects of lead. Also, because the immune system continues to develop during the postnatal growth period, variation in the immune system's rate of maturation could produce substantial differences in immune response among individuals. Given such variation, negative correlations between immune responsiveness and growth could result either from allocation of limited resources between growth and immune system function or from interference between the immune system and physiological controls of growth. Positive correlations between immune responsiveness and growth could result from variations in the overall condition of chicks that affect both the immune system and growth processes.

Due to the multitude of both pathogenic and nonpathogenic immunogens and contaminants to which wild birds may be exposed to during development, it is important to understand how the immune system and growth responds to both contaminants and immunogens together. The objectives of this study were to (1) determine the effects of two commonly used nonpathogenic antigens in concert with three levels of lead shot on survival, developmental stability, and growth of developing Japanese quail; (2) evaluate the use of commonly used hematological and growth parameters as indicators of exposure to lead shot or nonpathogenic antigens under controlled laboratory conditions; and (3) establish the relationship between the responsiveness of the immune system and several hematological parameters, growth, and FA.

\section{Materials and Methods}

\section{Animal Care and Experimental Design}

Unsexed Japanese quail (C. coturnix japonica: Pharaoh D1) were obtained at one day of age and acclimated to laboratory surroundings for 1 week before immunizations and measurements were begun. Quail were housed six to a cage in 12 cages measuring $61 \times 56 \times 81$ $\mathrm{cm}$. Temperature in the animal room was maintained at $23^{\circ} \mathrm{C}$. Food and water were available ad libitum. Quail were fed Purina Game Bird Startena ${ }^{\circledR}$ food containing approximately $30 \%$ crude protein that contained no coccidiostat or other medications. Fluorescent lights provided a photoperiod of $12 \mathrm{~h}$ light and $12 \mathrm{~h}$ dark. The University of Missouri-St. Louis Animal Care and Use Committee approved all protocols.

Eight Japanese quail were assigned randomly to each of nine groups in a $3 \times 3$ factorial design with three antigen treatments and three lead shot treatments (Table 1). There were 33 females and 38 males that were randomly assigned to each treatment, because sexing could not 
Table 1. Experimental $3 \times 3$ factorial design

\begin{tabular}{llll}
\hline & $\begin{array}{l}\text { No } \\
\text { Antigen } \\
(\mathrm{n})\end{array}$ & $\begin{array}{l}\text { Chukar } \\
\text { Red Blood } \\
\text { Cells (n) }\end{array}$ & $\begin{array}{l}\text { Newcastle } \\
\text { Disease } \\
\text { Virus (n) }\end{array}$ \\
\hline No lead Group & 7 & 8 & 8 \\
Low lead $(0.05 \mathrm{~g})$ & 8 & 8 & 8 \\
High lead $(0.2 \mathrm{~g})$ & 8 & 8 & 8 \\
\hline
\end{tabular}

be done until later in their development. Quail and treatments were randomly assigned to different cages to control for cage differences due to temperature, cage mates, light, etc. Quail were sometimes moved between cages if pecking started to occur. The lead shot treatments consisted of (1) a control or no-lead group, (2) a low-lead group, and (3) a high-lead group. The low- and high-lead groups received one $0.05 \mathrm{~g}$ (one \#9 shot) or $0.2 \mathrm{~g}$ (four \#9 shots), respectively, at 8 days of age. The dosages of the lead shot $(\mathrm{mg} / \mathrm{kg})$ varied due to the weights of the birds with a low lead treatment average of 2,354 $\mathrm{mg} / \mathrm{kg}(\mathrm{SD}=1,084)$ and the high $7,197.57 \mathrm{mg} / \mathrm{kg}(\mathrm{SD}=1,709)$. Lead dosage was used to mimic lead shot ingestion in the wild and estimate the lower end of previous published dosing studies.

Because Japanese quail respond poorly to immunization with sheep erythrocytes (Benton et al. 1977; Grasman 1992), subjects were immunized with chukar partridge (Alectoris graeca) erythrocytes (CRBCs), which evoke a higher antibody titer. CRBCs were obtained from game ranch chukars in Missouri. Quail were immunized with either $0.075 \mathrm{ml}$ of $10 \%$ CRBC suspension in phosphate-buffered saline (PBS), $0.075 \mathrm{ml}$ of Newcastle disease virus (NDV) (Fort Dodge Animal Health, Fort Dodge, IA), or a placebo vaccine carrier containing no antigen but the same amount of oil medium. All chicks were injected intraperitoneally (IP) at 13 days of age, and initial blood samples were drawn on the same day. A second injection of antigens was given on day 35 to investigate a secondary response. Birds were weighed and measured, and approximately $70 \mu \mathrm{l}$ of blood was drawn from the wing vein on day 13 and again on days $20,27,42$, and $49(0$, 7,14 , days post-primary injection and, 7 and 14 days post-secondary injection).

\section{Growth and FA}

Chicks were measured daily from day 6 though day 15 , then every 4 days until day 42. Tarsus length was measured to the nearest $0.01 \mathrm{~mm}$ using calipers. The length of the right wing was measured with a ruler to the nearest millimeter using the flattened-wing method (Svennson 1984). All of the birds were weighed on an electronic balance to the nearest $0.1 \mathrm{~g}$. After day 128 the birds were euthanized and examined internally to determine sex.

Fluctuating asymmetry was estimated for the length of the fifth and the first primary and the tarsus at 128 days of age. Each wing was removed and air-dried for several weeks. Due to the excessive wear from pecking on the first four primary and outermost feathers (numbers $10,9,8$, and 7), only primary feathers five and one were included in this analysis. The fifth and the first primary feathers were pulled and weighed on a top-loading analytical balance to the nearest $0.001 \mathrm{~g}$. Feathers could be cleanly removed from the wing. To estimate measurement error, each feather was weighed twice. FA was also estimated postmortem to the nearest $0.01 \mathrm{~mm}$. Tarsi were also measured twice to estimate measurement error. Seven quail that died after 75 days of age were included in the analysis of FA that as a group were found to not be different from all other quail. This gave a sample size of 63 quail for the FA analysis.

The statistical effects of interest are the right versus left side, individuals, and repeated measurements. The mean square for the side $\mathrm{x}$ individual interaction includes measurement error and nondirectional asymmetry, which consists of antisymmetry and FA Antisymmetry is distinguished from FA by producing a platykurtic or biomodal distribution, rather than a normal distribution, of the right-left difference around a mean of zero of FA (Palmer and Strobeck 1986). Thus, antisymmetry, which represents the exaggerated development or one side or the other, can be detected by testing the $\mathrm{R}-\mathrm{L}$ difference for normality. Measurement error is estimated directly.

\section{Antibody Response}

Blood (approximately $70 \mu \mathrm{l}$ ) was collected from the brachial vein of the wing in both heparinized and nonheparinized microcapillary tubes, which were kept at room temperature. Heparinized tubes were spun for $10 \mathrm{~min}$ in a microcapillary centrifuge within $1 \mathrm{~h}$ of collection. Nonheparinized tubes were centrifuged $12-15 \mathrm{~h}$ after collection. Plasma and serum were maintained at $4^{\circ} \mathrm{C}$ until analysis. Antibody responses to NDV were measured by a monoclonal antibody-blocking ELISA (Svanova Biotech, Sweden) (Czifra et al. 1996). Optical density (OD) was determined with an EL-312 Bio-Tek Instruments microtiter plate photometer. The lower the $\mathrm{OD}$, the greater the immune response.

Serum samples were heat-inactivated at $56^{\circ} \mathrm{C}$ for $30 \mathrm{~min}$, and agglutination of antibodies to CRBC antigens in sera was serially titrated. Antibody amounts or titers were determined with modified microtiter techniques (Wegmann and Smithies 1966). Titers were expressed as an inverse of the highest dilution showing hemagglutination, transformed to $\log _{2}$ scale (Brugh 1978), and scored using the method of Wegmann and Smithes (1966).

\section{Cell-Mediated Response and Nonspecific Immunity}

Cell-mediated immunity was measured using the dermal phytohemagglutinin (PHA) (Sigma Chemical Company, St. Louis, MO) reaction in the wing web. PHA injected for localized in vivo inflammatory response in birds has long been used to measure cell-mediated immunity (Stadecker et al. 1977; Lamont and Smyth 1984). Quail were inoculated intradermally on day 50 in the wing web with either $0.05 \mathrm{ml}$ of a $1.0 \mathrm{mg} / \mathrm{ml}$ PHA solution in PBS (right side) or $0.05 \mathrm{ml}$ PBS only (left side). The amount of swelling in the wing web $24 \mathrm{~h}$ after inoculation was measured by a micrometer to the nearest $0.001 \mathrm{~mm}$. A PHA index was computed as the width of the PHA-inoculated wing web minus the width of the opposite wing web and standardized for wing thickness (Fair et al. 1999)

$$
\text { PHA Index }=\frac{\text { postPHA }- \text { postPBS }}{\left(\frac{\text { prePHA }+ \text { prePBS }}{2}\right)}
$$

White blood cells (WBCs) classified according to Dein (1984) were counted on blood smears stained with Wright-Giemsa stain. Five randomly selected fields were examined using a $40 \times$ objective (Zeiss Axioskop microscope) for leukocyte counts. The reliability of this sampling design has been previously assessed by Apanius (1991), who determined that $82 \%$ of the observed variation could be attributed to differences between birds and that $18 \%$ was due to sampling error. Granulocytes were double-checked for identification using a $100 \times$ objective, and basophils were omitted because of their relative rarity. Results were analyzed both as total WBC and differentially grouped as lymphocytes (LHM), granulocytes (GRAN), eosinophils (EOSIN), monocytes (MONO), and total WBCs minus thrombocytes.

Hematocrits of blood collected in heparinized capillary tubes were determined directly on a microhematocrit reader. Total plasma protein 
was estimated using a refractometer (Westover Model RHC-200). Although it has been suggested that the refractometric method may be unreliable for determining plasma protein concentrations in pigeons (Lumeij and de Bruijne 1985), refractometers are commonly used in clinical practice and have been shown to be reliable for mammalian plasma (Schalm et al. 1975) and American kestrels (Dawson and Bortolotti 1997).

\section{Metabolic Rate}

Metabolic rate of quail was determined once later in development on day 128 of age. Birds were maintained on a 12 h (6 AM-6 PM) light-dark schedule, and all resting metabolic rates were measured after 9 PM. Birds were not fed for $3 \mathrm{~h}$ prior to metabolism trials, which therefore measured basal metabolic rate (BMR). Total body weight (digital scale, $0.01 \mathrm{~g}$ ) and the lengths of the tarsus and wing were recorded prior to each trial. Cloacal temperatures were measured at the beginning and end of the test with a thermocouple probe and Techmaster digital thermometer. Oxygen consumption was measured in an open flow respirometer by placing birds in a darkened Plexiglas chamber with water jackets on two sides connected to a circulating water bath for temperature control. Temperature was maintained at $30 \pm 1{ }^{\circ} \mathrm{C}$ and the airflow through the metabolic chamber was maintained at $804 \mathrm{cc} / \mathrm{min}$ by Brooks mass flow controllers. In-current air was passed under pressure through tubes containing Drierite ${ }^{\mathrm{TM}}$ (anhydrous calcium sulfate) to remove water vapor and soda lime (sodium hydroxide and calcium oxide) to remove carbon dioxide. Excurrent air was similarly passed through Drierite and soda lime. Concentration of oxygen in the excurrent air was determined with an Applied Electrochemistry S3A oxygen analyzer. Birds sat in the chamber undisturbed for $20 \mathrm{~min}$ once the levels reached a plateau, before oxygen consumption was recorded. Data were acquired by hand every $5 \mathrm{~min}$ for the next $50 \mathrm{~min}$. Preliminary trials revealed that oxygen consumption reached a plateau after $40 \mathrm{~min}$ of recording data and did not vary more than $5 \%$ after that period. The rate of oxygen consumption was calculated with Equation 4a of Withers (1977). Oxygen consumption $\left(\mathrm{VO}_{2}\right)$ was converted to energy assuming a caloric equivalent of 4.8 $\mathrm{kcal} / \mathrm{L} \mathrm{O}_{2}(1 \mathrm{kcal}=4.184 \mathrm{~kJ})$. Metabolic rate was estimated using the equation:

$$
\log \mathrm{VO}_{2}=-6.9+1.72 \log \text { weight. }
$$

\section{Analysis of Lead Concentrations in Blood and Postmortem Analysis}

Fifteen quail that received no antigens were chosen for lead blood analysis (six high dose, five low dose, and four no dose). Blood samples were collected once on day 49 and once on day 128. Lead concentrations from whole blood were analyzed by an atomic absorption spectrograph equipped with a graphite furnace atomizer. Quail were euthanized at 128 days of age, frozen, and internally sexed; then livers and spleens were extracted and weighed.

\section{Data Analysis}

The Statistical Analysis System (SAS Institute 1987) was used for all statistical analyses, and assumptions for parametric statistics were examined. Differences in survival of chicks in antigen and lead treatment groups were tested using PROC LIFETEST and employing the log rank statistic, which is more robust than the Wilcoxon statistic in detecting differences between groups later in time (Allison 1995).
Growth and physiological parameters were compared among antigen and lead treatments by repeated measures analyses of variance (ANOVAs) with antigen (3 levels), $\mathrm{Pb}$ treatments (3 levels), and time of observation (5 blood measurements for immunology and hematology measurements and 28 growth measurement periods) as fixed effects. Means for each treatment for each time period were also compared a priori with Duncan's multiple range test. The metabolic rates were log-transformed for the analyses for normality. Because of significant $(\mathrm{p}<0.001)$ interactions between time and antigen and/or $\mathrm{Pb}$ treatments, further ANOVAs were performed on each time period.

Growth trajectories were compared statistically among lead and antigen treatments using ANCOVA with age as the covariate. Growth curves were first fit to a variety of nonlinear models (SigmaPlot ${ }^{\circledR}$, SPSS Science, Chicago, IL) and the best-fitting model selected according to Akaike's information criterion, which is a likelihood-ratio test for goodness of fit (Akaike 1977) (Weibull, Richard's, and Logistic models were tested). The growth parameters asymptotic body mass $(\mathrm{g})$, growth rate, and point of inflection were estimated for each individual bird using the best fitting model, the Weibull distribution (parameterized from SigmaPlot ${ }^{\circledR}$ ):

$$
y=a\left[1-e-\left(\frac{x-x_{o}+b \ln 2^{1 / c}}{b}\right)^{c}\right]
$$

Other variables measured at each blood-sampling time, such as hematocrit or WBC counts, were analyzed for antigen and sex differences using repeated measures ANOVA. Regression analysis was used to test for correlations between hematocrit and plasma protein for each age. Analysis of FA included the determination of measurement error by comparing the duplicate measurements of each feather. The pattern of variation in the mass of feathers between individuals and between right and left wings was quantified for each primary feather by a two-way, mixed-model ANOVA according to Palmer and Strobeck (1986). Repeat measurements were used from each feather on each side to estimate measurement error. Three statistical tests were used in this analysis: (1) $F$ ([bird $\times$ wing]/error) estimates the magnitude of nondirectional asymmetry (antisymmetry and FA); (2) $F$ (bird/[bird $X$ wing]) estimates the magnitude of size variation among individual birds; and (3) $F$ (wing/[bird $\times$ wing]) estimates the magnitude of directional asymmetry. Antisymmetry is expressed as platykurtosis in the distribution of right $(\mathrm{R})$ - left $(\mathrm{L})$ differences (Palmer and Strobeck 1986) and is estimated. Accordingly, the $\mathrm{R}-\mathrm{L}$ distributions were tested for each feather one through five for normality. A variance component $V$ was calculated for the primary feathers one through five of each individual as the square of the normalized difference of the left and right sides (Fair et al. 1999);

$$
V=\left[\frac{2(R-L)}{R+L}\right]^{2}
$$

An FA index was then calculated for each individual as the square root of the variance components of each feather one and five, which is a measure of the individual contribution of FA expressed as a decimal fraction of the average feather mass. FA for each bird was then analyzed in a multiway ANOVA in which the effects were treatment and sex. We also determined whether FA was correlated with PHA skin response, hematocrit, plasma protein, and growth in ANCOVAs with sex entered as an effect.

\section{Results}

\section{Survival and Blood Lead Concentration}

Thirteen of the 72 quail died before the end of the experiment, and these quail were from all treatment groups. Four of the 
quail died before 20 days of age and nine after day 75 . None of the quail exhibited characteristic signs of lead poisoning, which include lethargy, anorexia, wing drop, regurgitation, diarrhea, ataxia, head tilt, blindness, tremors, and paralysis (Ritchie et al. 1994). There were no differences in the survival functions between the lead treatment groups $\left(\chi_{2}^{2}=1.98, \mathrm{p}=0.37\right.$ log-rank test $)$, the antigen groups $\left(\chi_{2}^{2}=1.23, p=0.54\right)$, or any of the nine treatment survivorship functions $\left(\chi_{8}^{2}=12.24, \mathrm{p}=\right.$ $0.14)$. There were no cage effects or patterns for any of the variables measured.

Concentrations of lead in blood from low- and high-dosed quail from both blood collection dates were elevated over the quail that received no lead $\left(F_{2,24}=5.38, \mathrm{p}=0.01\right)$, and but was no large age $\times$ treatment interaction $\left(F_{2,24}=3.25, \mathrm{p}=\right.$ $0.06)$. Concentrations of lead in blood differed between treatments on day $49\left(F_{2,12}=7.46, \mathrm{p}=0.008\right)$ but not on day 128 $\left(F_{2,12}=0.61, \mathrm{p}=0.56\right)$ (Figure 1$)$. The regression of lead concentration in blood on lead dose $(\mathrm{mg} / \mathrm{kg})$ was analyzed by the model having the form

$$
\log Y=\beta_{o}+\beta_{1} \log X
$$

where $\log Y$ is $\log _{10}$ blood lead concentration (ppm), $\beta_{0}$ is the regression intercept estimated by $b_{0}$. $\beta_{1}$ is the regression slope estimated by $b_{1}$, and $\log X$ is the $\log _{10}$ of $\mathrm{mg} / \mathrm{kg}$ lead dose. The ANOVA-generated regression line for blood lead concentrations is

$$
\log Y=-3.32(\mathrm{SE}=0.38)+0.47(\mathrm{SE}=0.12) \log X
$$

with $r^{2}=0.53$

Quail blood lead concentrations returned to nondosed levels by day 128 although the blood lead concentrations of control birds had increased by this time. This could be due to exposure to lead dust in the feces of treated birds over the time of the experiment. Purina Game Bird Startena contains no detectable background lead. Lead concentration in blood was unrelated to total plasma protein, hematocrit, right tarsus length, right wing length, or sex on either of the 2 days.

\section{Growth and Fluctuating Asymmetry}

Growth curves of the lead and antigen treatments did not appear to differ much prior to 56 days of age (Figure 2). Among the lead treatments, control birds achieved a higher asymptotic mass. The growth trajectory for body weight $(\mathrm{g})$ and right tarsus length $(\mathrm{mm})$ best fit a Weibull distribution (AIC criteria). Using the Weibull distribution, there were no differences in the lead treatments for body weight $\left(\chi_{2}^{2}=2.03\right.$, $\mathrm{p}=0.36)$, right tarsus $\left(\chi_{2}^{2}=1.02, \mathrm{p}=0.60\right)$, or any contrast between treatments (Table 2). There were also no differences in body weight $\left(\chi_{2}^{2}=0.65, \mathrm{p}=0.72\right)$, right tarsus between antigen treatments $\left(\chi_{2}^{2}=1.69, \mathrm{p}=0.43\right)$. When comparing treatments on day 60 when Japanese quail should have been fully grown, lead and antigen treatments did not differ.

Using the growth curve parameters of asymptotic body mass (g), logarithm growth rate, and inflection point for each individual, there were no differences in any of the lead or antigen treatments for any of the three growth parameters (Table 2).

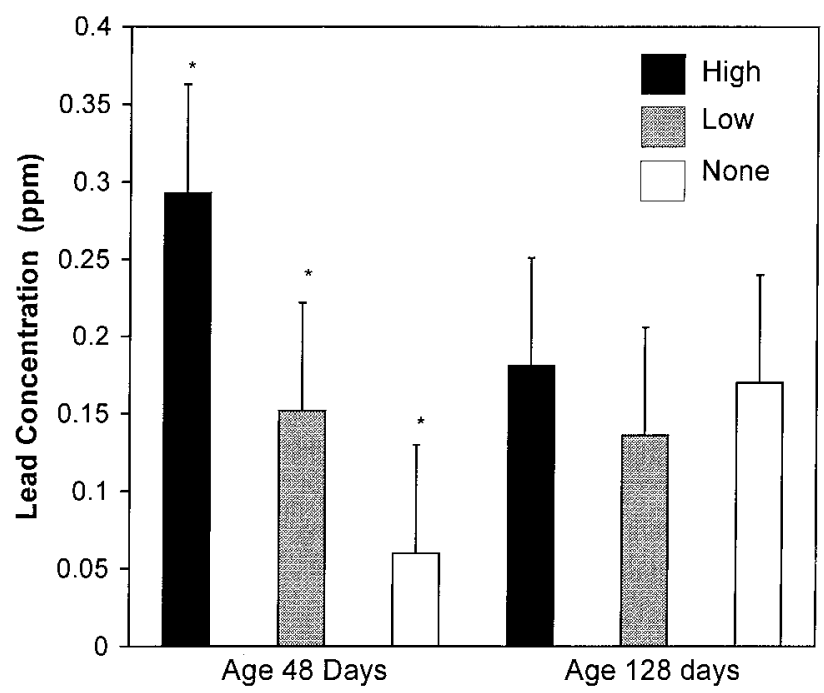

Fig. 1. Mean whole blood lead concentrations (ppm) of Japanese quail on day 49 and 128 of age ( + SD). *Denotes significantly different blood lead levels for day 49

There were also no interactions for antigens and lead treatments for the ANOVAs.

There was nondirectional FA in the weight of the fifth primary feather $\left(F_{62,126}=1.47, \mathrm{p}=0.02\right)$. FA varied between birds $\left(F_{62,126}=10.26, \mathrm{p}=0.0001\right)$, and no directional asymmetry was observed $\left(F_{1,126}=1.34, \mathrm{p}=0.25\right)$. Using the FA index for feathers one and five, there was no effect of lead on FA $\left(F_{2,54}=0.21, \mathrm{p}=0.81\right)$ or antigen $\left(F_{2,54}=0.84, \mathrm{p}=\right.$ $0.44)$, and there was no interaction between treatments. There was also no effect on sex. However, when the two feathers were analyzed individually, the antigen treatment had a significant effect on FA for feather five, with the NDV antigen having less FA than the placebo and the CRBC-treated birds had more FA than the placebo $\left(F_{2,117}=3.45, \mathrm{p}=0.03\right)$.

There was also nondirectional FA in the length of the tarsi $\left(F_{62,126}=23.50, \mathrm{p}=0.0001\right)$. FA varied between birds $\left(F_{62,126}=1307.8, \mathrm{p}=0.0001\right)$, and no directional asymmetry was observed $\left(F_{1,126}=0.11, \mathrm{p}=0.74\right)$. Using the FA variance there was no effect of lead on FA $\left(F_{2,54}=0.78, \mathrm{p}=0.46\right)$ or antigen $\left(F_{2,54}=1.69, \mathrm{p}=0.19\right)$ and there was no interaction.

\section{Antibody Response}

Change in NDV antibody concentration over time did not differ among the lead treatments $\left(F_{2,83}=0.95, \mathrm{p}=0.39\right.$, repeated measures) (Figure 3). Individual birds exhibited different levels of antibody production to NDV vaccine for both the primary and secondary immunizations. The low-lead group started off with a stronger immune secondary response than the high lead and control groups, which did not differ, although the actual response over time was the same. In general, antibody production to NDV was not reduced by the lead treatments.

Antibody response to the T-cell-dependent antigen, CRBC, varied more than the antibody response to the T-cell-independent antigen, NDV. The overall response curves over time 

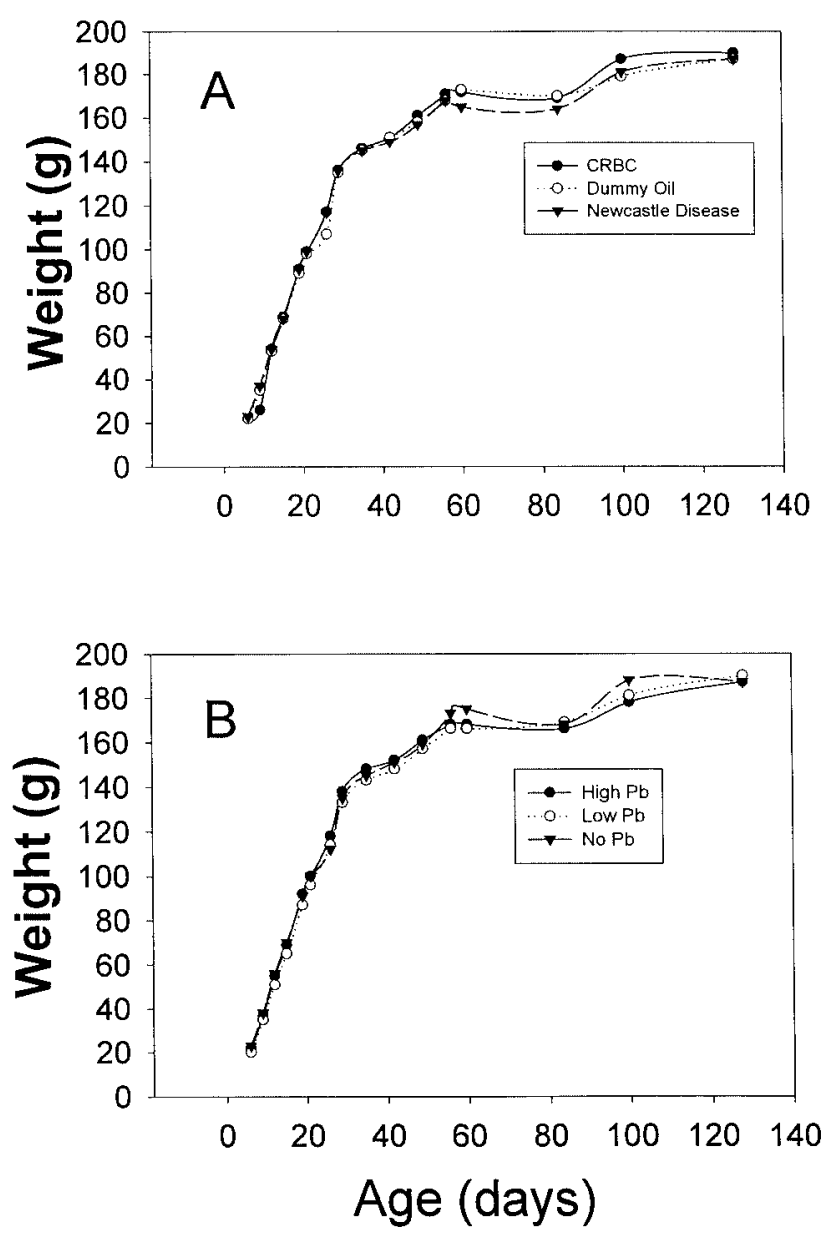

Fig. 2. Whole body weight (g) of Japanese quail over time. A: Antigen treatments; B: Lead treatments

differed between the three $\mathrm{Pb}$ treatments $\left(F_{2,57}=3.09, \mathrm{p}=\right.$ 0.05) (Figure 4). However, it is the overall change of the three treatment group's response over time that is significant, not within each immunization period (first: $F=1.81, \mathrm{p}=0.20$; second: $F=1.51, \mathrm{p}=0.25)$. Although for the secondary response 7 days postinjection of CRBC, both lead treatments were significantly different than the control quail.

\section{Cell-Mediated Response and Nonspecific Immunity}

Cell-mediated immune response to PHA was not reduced by the lead or antigen treatments, and there was no lead $\times$ antigen interaction $\left(F_{8,55}=1.34, \mathrm{p}=0.24\right)$ (Table 3$)$. Response to PHA also did not differ between sexes $\left(F_{1,55}=3.29, \mathrm{p}=0.07\right)$. Response to PHA also was not correlated with $\mathrm{Pb}$ dose $(\mathrm{mg} / \mathrm{kg})$ $\left(F_{1,42}=0.21, \mathrm{p}=0.65\right)$ or quail mass $\left(F_{1,63}=0.40, \mathrm{p}=0.53\right)$.

WBC numbers increased on day 27 and 49, both times 7 days after antigen injection $\left(F_{3,223}=5.69, \mathrm{p}=0.0009\right)$; WBC counts at 27 days of age were greater than the WBC counts at 49 days of age (Duncan's multiple range test). Sexes did not differ with respect to total WBC count $\left(F_{1,223}=0.13, \mathrm{p}=\right.$ $0.71)$ or to granulocytes $\left(F_{1,223}=7.72, \mathrm{p}=0.15\right)$. In all quail, granulocytes decreased from age 20 and 27 days to ages 42 and 47 days. Lymphocyte numbers did not change with age $\left(F_{3,223}=2.17, \mathrm{p}=0.09\right)$, and there was a larger number of lymphocytes in females $\left(F_{1,223}=4.31, \mathrm{p}=0.039\right)$.

There were no differences in total WBCs or lymphocytes on any of the 4 days for lead or antigen treatment. However, there were more granulocytes on day 20 from both lead treatments than from no lead treatment (mean high treatments $=8.6$, low $=7.5$, none $=5.2$, Duncan's multiple range test). Granulocyte counts from NDV- and CRBC-treated birds were lower than for birds treated with placebo (mean $\mathrm{CRBC}=5.4$, $\mathrm{NDV}=6.7$, and placebo $=10.7$, Duncan's multiple range test). By 17 days of age, granulocyte counts had returned to control values and there were no differences for either antigen or lead treatments for any of the remaining days beyond day 20 and no lead $\times$ antigen interactions.

\section{Hematology}

The pattern of change in quail hematocrits differed between the three lead treatments $\left(F_{2,420}=49.42, \mathrm{p}<0.0001\right.$, repeated measures), but differences were not correlated with dosage (Table 3). Antigen treatments did affect hematocrits over time $\left(F_{2,420}=4.82, \mathrm{p}=0.008\right)$, and there was no interaction between antigen and lead treatments $(F=1.29, \mathrm{p}=0.14)$. For the first blood drawing on day 6 , the control birds had significantly higher hematocrits (44\% versus $41 \%$ and $40 \%$ for the high and low lead treatments, respectively). This was also the case for 13 days of age and by 27 days of age only the high lead treatment quail hematocrits were lower and by day 128 there was no difference in lead treatments. For the antigen treatments, on day 13 of age, NDV-treated birds had significantly higher hematocrits than the oil for CRBC-treated quail. By day 49 hematocrits were similar for all treatments.

For the plasma protein, there was a significant interaction between the lead and antigen treatments $\left(F_{3,343}=19.35, \mathrm{p}<\right.$ $0.0001)$. The control treatment group was significantly higher than both lead treatment groups for every time period except day 6. The treatment groups of NDV with low and high lead exposure had an average total plasma protein of $14 \%$ lower than other groups.

\section{Metabolic Rate and Organ Analysis}

The metabolic rates were log-transformed for the analyses. There were no differences in mean metabolic rates for quail with antigen treatments $\left(F_{2,55}=0.83, \mathrm{p}=0.44\right)$ or Pb treatments $\left(F_{2,55}=0.64, \mathrm{p}=0.53\right)$, and the interaction term was not significant (Figure 5). However, metabolic rates of females exceeded those of males $\left(F_{1,54}=19.08, \mathrm{p}=0.0001\right)$, and mean metabolic rate increased with increasing body weight $\left(F_{1,62}=\right.$ 56.16, $\left.\mathrm{p}=0.0001, r^{2}=0.47\right)$.

Spleens and livers of 58 quail were analyzed postmortem. Mean spleen size did not differ between antigen treatments $\left(F_{2,47}=0.16, \mathrm{p}=0.85\right)$ or $\mathrm{Pb}$ treatments $\left(F_{2,47}=0.07, \mathrm{p}=\right.$ 0.93; no significant interaction term). There was a mean liver weight $6.5(\mathrm{SE}=0.50)$ for birds at the higher lead dosage, 6.2 $(\mathrm{SE}=0.58)$ for the low treatment birds, and 6.1 $(\mathrm{SE}=0.49)$ 
Table 2. Mean responses for ( $\pm 1 \mathrm{SE}$ ) of antigen and lead groups growth curve parameters asymptotic body mass, growth rate, and point of inflection for the Weibull nonlinear curve

\begin{tabular}{|c|c|c|c|c|}
\hline Lead & Antigen & Asymptotic Body Mass (g) & Growth Rate $(\log K)$ & Inflection Point \\
\hline High & CRBC & $179.77 \pm 7.2$ & $0.21 \pm 0.14$ & $23.38 \pm 1.4$ \\
\hline High & NDV & $182.91 \pm 19.8$ & $0.39 \pm 0.25$ & $37.8 \pm 11.9$ \\
\hline High & Dummy & $180.52 \pm 11.9$ & $0.60 \pm 0.17$ & $26.84 \pm 2.1$ \\
\hline Low & CRBC & $178.69 \pm 10.4$ & $0.30 \pm 0.12$ & $23.30 \pm 0.44$ \\
\hline Low & NDV & $183.09 \pm 7.1$ & $0.30 \pm 0.15$ & $26.36 \pm 1.9$ \\
\hline Low & Dummy & $199.66 \pm 20.5$ & $0.20 \pm 0.26$ & $31.96 \pm 4.1$ \\
\hline None & CRBC & $180.7 \pm 7.8$ & $0.72 \pm 0.34$ & $24.67 \pm 0.9$ \\
\hline None & NDV & $202.86 \pm 11.16$ & $0.51 \pm 0.21$ & $25.69 \pm 1.0$ \\
\hline None & Dummy & $160.56 \pm 4.6$ & $0.04 \pm 0.20$ & $27.60 \pm 5.4$ \\
\hline
\end{tabular}
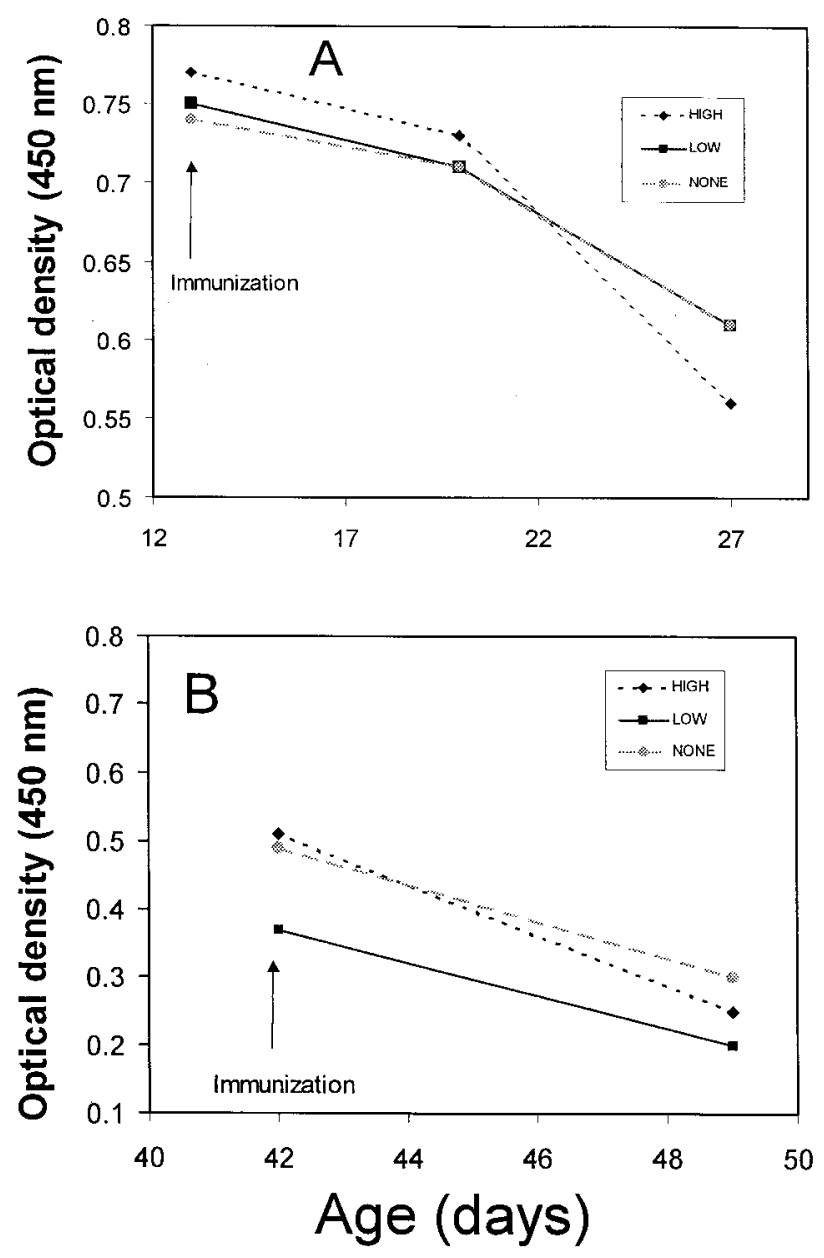

Fig. 3. Mean optical densities at $450 \mathrm{~nm}$ for the Newcastle disease virus-injected quail for three lead treatments over time. A: First immunization period, days 13, 20, and 27 of age; B: secondary immunization period, days 42 and 49 of age. Antibody response is inversely related to optical density, i.e., greater antibody response occurred at lower optical density

in the control birds, but the effect size was not significant $\left(F_{2,55}=0.65, \mathrm{p}=0.53\right)$. However, liver weights did not differ among antigen treatments $\left(F_{2,55}=0.35, \mathrm{p}=0.71\right)$. Livers were significantly larger in females than in males $\left(F_{1,55}=35.33\right.$, $\mathrm{p}=0.0001)$ but spleens of the two sexes did not differ $\left(F_{2,47}=\right.$
$0.09, \mathrm{p}=0.76)$. There was no relationship with liver mass and dose $(\log \mathrm{mg} / \mathrm{kg})\left(F_{1,36}=0.49, \mathrm{p}=0.49\right)$.

\section{Discussion}

In this study, lead concentrations in blood were much lower than reported in other studies of ingested lead shot; blood concentrations in treated birds increased initially, then decreased to control levels by 128 days of age. The concentration of lead in the blood up to 49 days of age in this study indicates that lead was absorbed from the digestive system. No lead shot was seen or collected in any of the gizzards, but one lead shot (\#4) is known to gradually dissolve in the gizzards of Japanese quail, disappearing between 9 and 32 days (Yamamoto et al. 1993). Yamamoto et al. (1993) found that although the destruction of lead pellets was rapid and absorption extended over a long period of time; he concluded that this would cause more of a chronic type of lead poisoning.

The most significant finding in this study did not have to do with the lead treatments but with the effect of the antigens on the FA in the quail. Antigen treatment had a significant effect on the larger and outermost of the two feathers measured. This study confirms the study of Fair et al. (1999) that primary feather FA can be affected by immunological challenge during growth and that FA increases with respect to the size of the feather. The interesting aspect of the FA of feather five is that NDV-treated birds contained more FA than the placebo birds and the CRBC-treated birds contained less FA. However, this is similar to the results of Fair et al. (1999) that NDV-treated quail had less primary feather FA than SRBC-treated quail. There was no antigen-related FA in the smallest feather, closest to the body, and no evidence was found that the additional stress of lead added to FA in the quail (i.e., no antigen-lead interaction). More understanding is needed of the antigenic, cellular, and energetic responses of the organisms to different types of antigens.

As in several other studies, this study failed to observe an increase in FA under the added stress of contaminant exposure. For example, Clarke (1993b) found that atmospheric pollution did not increase wing FA in the lacewing (Chrysopa perla). Hurtado et al. (1997) did not find increased FA in the fruit fly (Drosophila pachea) in response to the environmental stress of host plant variability, which is known to influence growth. It is becoming clear that increases in FA in response to stressors 


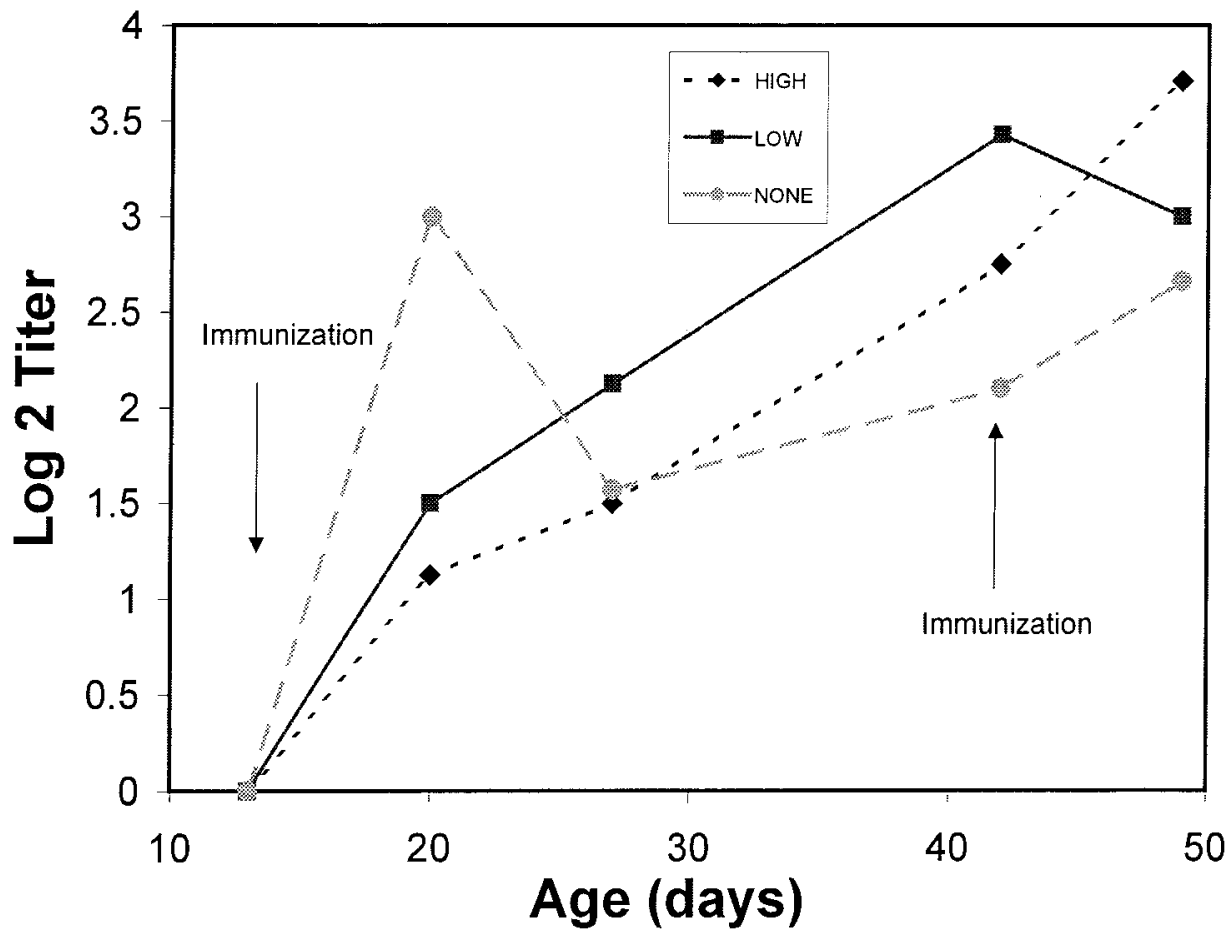

Fig. 4. Mean hemagglutination $\log _{2}$ titers for the three lead treatments and two immunizations with CRBC

Table 3. Mean responses for ( $\pm 1 \mathrm{SE})$ of antigen and lead groups for blood $\mathrm{Pb}$ concentration at 48 days of age, hematocrit, metabolic rate, liver weight, spleen weight, and PHA response

\begin{tabular}{|c|c|c|c|c|c|c|c|c|}
\hline $\begin{array}{l}\text { Lead } \\
\text { Treatment }\end{array}$ & Antigen & $\begin{array}{l}\text { Blood } \mathrm{Pb} \\
(\mathrm{ppm}) \\
48 \text { days }\end{array}$ & $\begin{array}{l}\text { Hematocrit } \\
(\%)\end{array}$ & $\begin{array}{l}\text { Total Plasma } \\
\text { Protein } \\
\left(\mathrm{g} \mathrm{dl}^{-1}\right)\end{array}$ & $\begin{array}{l}\text { Log } \\
\text { Metabolic } \\
\text { Rate }\left(\mathrm{VO}_{2}\right)\end{array}$ & Liver (g) & Spleen (g) & $\begin{array}{l}\text { PHA } \\
\text { Index }\end{array}$ \\
\hline \multirow[t]{3}{*}{ High } & NDV & N/A & $43 \pm 0.9$ & $3.5 \pm 0.1$ & $1.9 \pm 0.07$ & $6.0 \pm 0.80$ & $0.14 \pm 0.04$ & $0.37 \pm 0.1$ \\
\hline & CRBC & N/A & $44 \pm 1.3$ & $3.9 \pm 0.2$ & $2.1 \pm 0.13$ & $7.5 \pm 0.54$ & $0.2 \pm 0.04$ & $0.67 \pm 0.1$ \\
\hline & Dummy & $0.29 \pm 0.05^{*}$ & $43 \pm 1.0$ & $3.9 \pm 0.2$ & $1.9 \pm 0.07$ & $6.4 \pm 1.14$ & $0.08 \pm 0.02$ & $0.33 \pm 0.2$ \\
\hline \multirow[t]{3}{*}{ Low } & NDV & N/A & $43 \pm 1.1$ & $3.3 \pm 0.1$ & $2.0 \pm 0.11$ & $6.1 \pm 0.91$ & $0.09 \pm 0.02$ & $0.64 \pm 0.1$ \\
\hline & CRBC & N/A & $43 \pm 0.9$ & $3.4 \pm 0.1$ & $2.1 \pm 0.17$ & $5.9 \pm 1.1$ & $0.13 \pm 0.03$ & $0.41 \pm 0.1$ \\
\hline & Dummy & $0.15 \pm 0.04 *$ & $43 \pm 1.2$ & $3.8 \pm 0.2$ & $2.2 \pm 0.22$ & $6.8 \pm 0.96$ & $0.19 \pm 0.08$ & $0.51 \pm 0.1$ \\
\hline \multirow[t]{3}{*}{ None } & NDV & N/A & $44 \pm 1.1$ & $3.3 \pm 0.1$ & $2.2 \pm 0.15$ & $6.7 \pm 0.87$ & $0.16 \pm 0.04$ & $0.53 \pm 0.1$ \\
\hline & CRBC & N/A & $42 \pm 0.9$ & $3.5 \pm 0.1$ & $2.2 \pm 0.12$ & $6.2 \pm 0.7$ & $0.14 \pm 0.03$ & $0.56 \pm 0.1$ \\
\hline & Dummy & $0.06 \pm .04 *$ & $45 \pm 1.3$ & $3.9 \pm 0.2$ & $1.8 \pm 0.15$ & $4.3 \pm .10$ & $0.12 \pm 0.02$ & $0.34 \pm 0.2$ \\
\hline
\end{tabular}

* Significantly different on day 48 of age between lead shot treatments.

varies with the stress, the species, and the environment, and that more research is needed to demarcate the mechanism behind FA.

Quail did not exhibit marked physiological responses to antigen treatments, lead treatments, or a combination of the two. Lead is considerably more toxic to nestling American kestrels, an altricial species, than it is for the young of precocial species, such as quail (Hoffman et al. 1985). Based on a study of European starlings, Grue et al. (1986) also concluded that altricial species are more sensitive to lead exposure than precocial species. However, for some hematological parameters, Custer et al. (1984) found no effect of a diet with biologically incorporated in chickens with lead acetate on packed-cell volume of Falco sparverius. Morgan et al. (1975) found that lead acetate $(500 \mathrm{ppm})$ inhibited growth and caused anemia in Japanese quail, a precocial species, but did not depress the immune response to sheep erythrocytes even at levels as high as $1,000 \mathrm{ppm}$. However, this result was confounded by the fact that Japanese quail respond poorly to sheep erythrocytes. Vengris and Maré (1974) found a similar lack of effect of lead on the immune system of precocial chickens given aqueous lead acetate for 35 consecutive days. They could tolerate doses of as much as $160 \mathrm{mg} \mathrm{kg}^{-1}$ day $^{-1}$ and blood lead concentrations of $6.2 \mathrm{ppm}, 20$ times the level recorded in this present study. Redig et al. (1991) showed that short-term, low-level lead exposure (lead acetate administered orally) did not affect immune function significantly in red-tailed hawks. One dose of lead shot, although thought to be chronic because it slowly erodes in the gizzard, is not enough to impair immune function in birds. However, shot size or the lead form may greatly affect the outcomes of immunology-lead experiments.

Cell-mediated immunity showed weak response to the lead and antigen treatments. Grasman and Scanlon (1995) found a negative response to PHA in Japanese quail fed a low-protein 


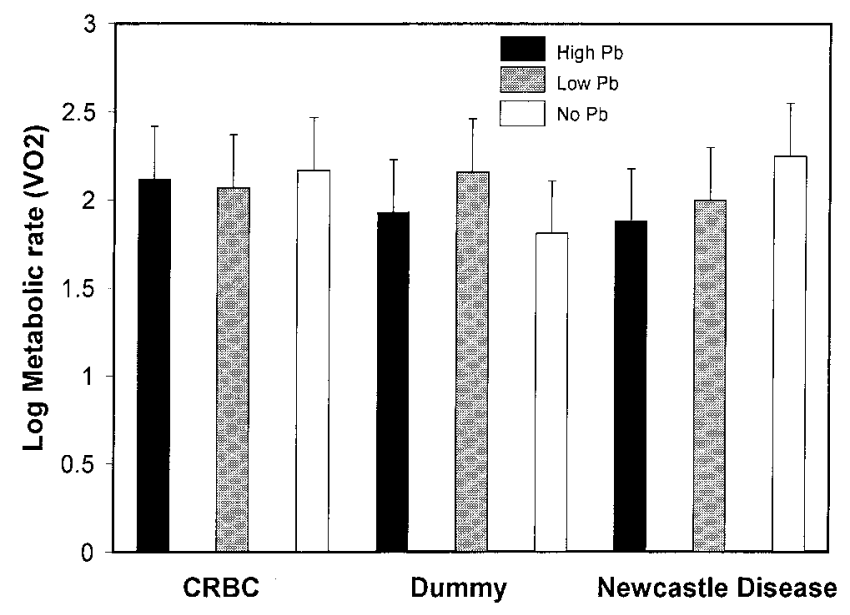

Fig. 5. Mean log metabolic rate $\left(\mathrm{VO}_{2}\right)$ for Japanese quail for the nine treatments

diet of corn and exposed to lead shot, and they did not find an effect on the PHA response in the high-protein (15\%) diet. Because the cell-mediated response develops later in birds, PHA was administered in this study well after the initial lead dose, by which time blood lead could have decreased to levels that do not affect cell-mediated immunity. In this study, the long-term effects of lead exposure on quail were evaluated with PHA tests because blood lead levels can stay elevated from lead shot for up to 6 weeks. The Japanese quail in this experiment received a diet containing approximately $30 \%$ protein. Grasman and Scanlon (1995) showed that diet is a more important potential stressor than immunological challenge during chick development, and can have additive effects with lead exposure.

Other studies (Trust et al. 1990; Rocke and Samuel 1991) have demonstrated that lead can suppress antibody response at low doses. Field studies have demonstrated simultaneous lead poisoning and pathogenic infections in wild birds (Locke and Bagley 1967; Locke et al. 1978; Rocke and Samuel 1991). These studies support the hypothesis that lead may be an ultimate cause of deaths related to other factors; however, our study shows that this is unlikely to be important with respect to a single small dose of lead shot. Hematocrit and total plasma proteins were affected by lead; protein was affected by lead and antigen treatments. Because lead interferes with heme synthesis, resulting in anemia, hematocrit was expected to be lower in lead-dosed birds, a result shown in this study and by Grasman and Scanlon (1995).

Lead ingestion causing the livers of Japanese quail to increase in size has been described by Yamamoto et al. (1993). This study did not detect an increase in liver size. Other investigators (Kendall and Scanlon 1981; Mautino and Boll 1987) found that bone, liver, and kidney accumulate most of the ingested lead. The spleen sequesters lead-damaged erythrocytes and increases in size (Ogilvie and Martin 1981). Quail in this experiment exhibited no lead-induced splenomegaly. Ogilvie and Martin (1981) found that spleens of mice that had been exposed to lead acetate for 6 weeks were $29 \%$ heavier, while the spleens of mice that had ingested $5 \mathrm{mg} / \mathrm{ml}$ of lead acetate for 5 to 10 months were $130 \%$ heavier than the spleens of the controls. Other studies showing an increase in spleen weights were based on more bioavailable and chronic doses of lead. Thus erythrocyte damage probably does not occur to a great extent in birds that ingest a single lead shot.

Using the immunological data from two immunotoxicology studies, power was estimated a priori for their total WBC counts (Trust et al. 1994) and hemagglutination titers (Trust et al. 1990). Power was basically one for each parameter starting at a sample size of 6 for the WBC counts for Sturnus vulgaris and 12 for the hemagglutination titers for Anas platyrhynchos per treatment group (SAS Institute). In the absence of preliminary data on the various immune responses and the variance that could be expected, the above studies offered an idea of potential sample sizes that would provide acceptable statistical power to avoid committing a type II error. Variance in this study was similar to the above studies and offer a greater reliability of the no effects results of this study, although the hemagglutination treatments gave a power of approximately 0.80 .

Granulocytes, and heterophils in particular, have been used as indicators of a stress response in birds (Gross and Siegel 1983; Grassman and Scanlon 1995). This study adds more evidence that granulocytes or a heterophil/lymphocyte ratio can be used to indicate stress of lead exposure. However, the granulocyte levels in birds in this study returned to control levels by age 27 days. Gross and Siegel (1986) found that birds had a similar heterophil rise to a second stress of fasting after a first fasting, indicating that birds can adjust this stress response. This may also be the case for chronic exposure of contaminants, suggesting that this indicator of stress may be only good for a short time period after an acute stress.

Between lead or antigen treatments, there were no differences in the ultimate endpoint of survival. Response to lead could be mediated by direct toxic effects on immune cells or organs, by lead-induced nutritional deficiencies, or by an adrenal stress response. Further research is needed to elucidate the mechanism behind the suppressive effects of lead as well as the long-term effects of exposure to stressors during development. The mechanism behind a trade-off in immunocompetence and growth is also needed to help determine the magnitude and importance of such a trade-off. In this study, there were no distinct relationships with immunocompetence or antibody production and hematological or growth parameters. Currently, the relationship between immunocompetence and survival is unknown in birds and is crucial to the understanding of the ultimate importance of immune function or suppression on individuals and populations.

Acknowledgments. We thank C. McGregor for the helpful care and feeding of the Japanese quail and B. Hardardóttir, M. Crenshaw, R. Dyer, L. Marsh, C. Thorstad and S. Whitaker for thoughtful assistance throughout the project. We thank O. Myers, M. Ebinger, and R. Mirenda for comments on an earlier draft. Special thanks to L. Solholt and $\mathrm{O}$. Myers for funding support. This research was funded by the U.S. Department of Energy contract no. W-7405-ENG-36 to Los Alamos National Laboratory and the LANL Environmental Restoration Project. 


\section{References}

Akaike H (1977) On the entropy maximum principle. In: Krishnaiah PR (ed) Applications of statistics. North Holling Publishing Co, Amsterdam

Allison J (1955) Biological evaluation of proteins. Physiol Rev 35: $664-700$

Allison P (1995) Survival analysis using the $\mathrm{SAS}^{\circledR}$ system: a practical guide. SAS Institute Inc., Cary, NC

Apanius V (1991) Blood parasitism, immunity and reproduction in American kestrels (Falco sparverius L.). Ph.D. diss., University of Pennsylvania

Benton EH, Morgan GW, Thaxton P, Parkhurst CR, Shambley MO (1977) Antibody responses to xeogeneic red blood cell challenge in Japanese quail. Immunol Commun 6:259-265

Bernhard Rabitsch W (1997) Levels of asymmetry in Formica pratensis Retz. (Hymenoptera, Insecta) from a chronic metal-contaminated site. Environ Toxicol Chem 16:1433-1440

Bonn A, Gasse M, Rolff J, Marten A (1996) Increased fluctuating asymmetry in the damselfy Coenagrion puella is correlated with ectoparasitic water mites: implications for fluctuating asymmetry. Oecologia 108:596-598

Brugh M (1978) A simple method for recording and analyzing serological data. Avian Dis 22:362-365

Clarke GM (1993a) Fluctuating asymmetry of invertebrate populations as a biological indicator of environmental quality. Environ Pollution 82:207-211

Clarke GM (1993b) Patterns of developmental stability in Chrysopa perla L (Neuroptera: Chrysopidae) in response to environmental pollution. Environ Entomol 22:1362-1366

Custer T, Franson J, Pattee O (1984) Tissue distribution and hematologic effects in American kestrels (Falco sparverius L.) fed biologically incorporated lead. J Wildl Dis 20:39-43

Czifra G, Nilsson M, Alexander D, Manvell R, Kechskemett, Engstrom B (1996) Detection of PMV-1 specific antibodies with a monoclonal antibody blocking enzyme-linked immunosorbent assay. Avian Pathol 25:691-703

Dawson R, Bortolotti G (1997) Total plasma protein level as an indicator of condition in wild American kestrels (Falco sparverius). Can J Zool 75:680-686

Dein F (1984) Laboratory manual of avian hematology. Association of American Veterinarians. East Northport. NY

Eeva T, Lehikoinen E (1996) Growth and mortality of nestling great tits (Parus major) and pied flycatchers (Ficedula hypoleuca) in a heavy metal pollution gradient. Oecologia 108:631-639

Fair J, Hansen E, Ricklefs R (1999) Growth, developmental stability and immune response in juvenile Japanese quails (Coturnix coturnix japonica). Proc R Soc Lond B 266:1735-1742

Franson JC (1984) "Immunosuppressive effects of lead." In: Feierabend JS, Russel AB (eds) Lead poisoning in wild waterfowl-a workshop. National Wildlife Federation, Washington, DC, pp $106-108$

Gebhardt-Henrich S, Richner H (1998) "Causes of growth variation and its consequences for fitness.” In: Starck J, Ricklefs R (eds) Avian growth and development. Oxford University Press, New York, pp 324-339

Grasman KA (1992) Effects of lead ingestion on immune function in quail. MS thesis, Virginia Tech University, Blacksburg

Grasman KA, Scanlon PF (1995) Effects of acute lead ingestion and diet on antibody and T-cell-mediated immunity in Japanese quail. Arch Environ Contam Toxicol 28:161-167

Gross WB, Siegel PB (1983) Evaluation of the heterophil-lymphocyte ratio as a measure of stress in chickens. Avian Dis 27:972-979

Gross WB, Siegel PB (1986) Effects of initial and second periods of fasting on heterophils/lymphocyte rates and body weight. Avian Dis 30:345-346
Grue CE, Hoffman DJ, Beyer WN, Franson LP (1986) Lead concentrations and reproductive success in European starlings Sturnus vulgaris near signs within highway roadside verges. Environ Pollut 42:157-182

Hoffman DJ, Franson C, Pattee OH, Bunck CM, Anderson A (1985) Survival, growth, and accumulation of ingested lead in nestling American kestrels (Falco sparverius). Arch Environ Contam Toxicol 14:89-94

Hurtado L, Castrezana S, Mateos M, McLaurin D, Karey Tello M, Campoy J, Markow T (1997) Developmental stability and environmental stress in natural populations of Drosophila pachea. Ecotoxicol 6:233-238

Kendall RJ, Scanlon PF (1981) Tissue lead concentration in Japanese quail ingesting lead pellets or shot with lead pellets. Bull Environ Contam Toxicol 26:652-655

Klasing K (1998) Nutritional modulation of resistance to infectious diseases. Poultry Sci 77:1119-1125

Klasing K, Laurin L, Peng R, Fry M (1987) Immunologically mediated growth depression in chicks: influence of feed intake, corticosterone and interleukin-1. J Nutr 117:1629-1637

Koller LD (1973) Immunosuppression produced by lead, cadmium and mercury. Am J Vet Res 34:1457-1458

Lamont S, Smyth J (1984) Effect of selection for delayed amelanosis on immune response in chickens. 2. Cell-mediated immunity. Poultry Sci 63:440-442

Leveille G, Sauberlich H (1961) Influence of dietary protein level on serum protein components and cholesterol in the growing chick. $\mathrm{J}$ Nutr 74:500-504

Locke LN, Bagley GE (1967) Case report: coccidiosis and lead poisoning in Canada geese. Chesapeake Sci 8:68-69

Locke LN, Bagley GE, Frickie CA (1978) Lead poisoning and aspergillosis in an Andean condor. J Am Vet Med Assoc 155:10521056

Lumeij J, de Bruijne J (1985) Evaluation of the refractometric method for determination of total protein in avian plasma or serum. Avian Pathol 14:441-444

Mautino M, Bell JU (1987) Hematological evaluation of lead intoxication in mallards. Bull Environ Contam Toxicol 38:78-85

Moller A, Swaddle J (1997) Asymmetry, developmental stability, and evolution. Oxford University Press, Oxford

Morgan GW, Edens FW, Thaxton P, Parkhurst CR (1975) Toxicity of dietary lead in Japanese quail. Poultry Sci 54:1636-1642

Nelson N, Lakshmanan, Lamont S (1995) Sheep red blood cells and Brucella abortus antibody responsiveness in chickens for multitrait immunocompetence. Poultry Sci 74:1603-1609

Ogilvie DM, Martin AH (1981) Splenomegaly and adrenal weight changes in isolated adult mice chronically exposed to lead. Bull Environ Contam Toxicol 26:647-651

Palmer R, Strobeck C (1986) Fluctuating asymmetry: measurement, analysis, patterns. Ann Rev Ecol Syst 17:391-421

Redig PT, Lawler EM, Schwartz S, Dunnette JL, Stephenson B, Duke G (1991) Effects of chronic exposure to sublethal concentrations of lead acetate on heme synthesis and immune function in redtailed hawks. Arch Environ Contam Toxicol 21:72-77

Richner H, Schneiter P, Stirnimann H (1989) Life-history consequences of growth rate depression: an experimental study on carrion crows (Corvus corone corone L.). Funct Ecol 3:617-624

Ritchie BW, Harrison GJ, Harrison LR (1994) Avian medicine: principle and application. Wingers Publishing, Lake Worth, FL

Rocke TE, Samuel MD (1991) Effects of lead shot ingestion on selected cells of the mallard immune system. J Wildl Dis 27:1-9

Romijn C, Graue R, Guth J, Harrison E, Jackson C, Lefebvre B, Smith W, Street J (1995) The use of Japanese and bobwhite quail as an indicator species in avian toxicity test. Chemosphere 30:10331040

Sarre S (1996) Habitat fragmentation promotes fluctuating asymmetry 
but not morphological divergence in two geckos. Res Popul Ecol 38:57-64

SAS Institute (1987) SAS/STAT guide for personal computers, 6 th ed. SAS Institute, Cary, NC

Schalm OW, Jain NC, Carroll EJ (1975) Veterinary hematology. 3d ed. Lea and Febiger, Philadelphia, PA

Stadecker M, Lukic M, Dvorak A, Leaskowitz S (1977) The cutaneous basophil response to phytohemagglutinin in chickens. J Immunol 118:1564-1568

Stanton ML, Roy BA (1999) Asymmetry in wild mustard, Sinapis arvensis (Brassicaceae), in response to severe physiological stresses. J Evol Biol 12:440-449

Svennson L (1984) Identification guide to European passerines, 2d ed. Stockholm, Sweden

Svensson E, Råberg L, Koch C, Hasselquist D (1998) Energetic stress, immunosuppression and the costs of an antibody response. Funct Ecol 12:912-919

Swaddle J, Whitter M (1994) Food, feathers and fluctuating asymmmetries. Proc R Soc Lond B 255:147-152

Teather K (1996) Patterns of growth and asymmetry in nestling tree swallows. Avian Biol 27:302-310
Trust KA, Fairbrother A, Hooper MJ (1994) Effects of 7,12-dimethylbenz[a]anthracene on immune function and mixed-function oxygenase activity in the European starling. Eviron Toxic Chem $13: 821-830$

Trust KA, Miller MW, Ringleman JK, Orme IM (1990) Effects of ingested lead on antibody production in mallards (Anas platyrhynchos). J Wildl Dis 26:316-322

Vengris VE, Maré CJ (1974) Lead poisoning in chickens and the effects of lead on interferon and antibody production. Can J Comp Med 38:328-335

Wegmann T, Smithies O (1966) A simple hemagglutination system requiring small amounts of red cells and antibodies. Transfusion 6:67-73

Withers PC (1977) Measurement of $\mathrm{VO}_{2}, \mathrm{VcO}_{2}$ and evaporative water loss with a flow-through mask. J Appl Physiol 42:120-123

Yamamoto K, Hayashi M, Yoshimura M, Hayashi H, Hiratsuka A, Isii Y (1993) The prevalence and retention of lead pellets in Japanese quail. Arch Environ Contam Toxicol 24:478-482

Youssef SAH (1996) Effect of subclinical lead toxicity on the immune response of chickens to Newcastle disease virus vaccine. Res Vet Sci 60:13-16 